JPE 10-1-3

\title{
A Tightly Regulated Triple Output Asymmetrical Half Bridge Flyback Converter
}

\author{
Byeong-Cheol Hyeon ${ }^{\dagger}$ and Bo-Hyung Cho* \\ $\dagger *$ Dept. of Electrical and Electronics Eng., Seoul National University, Seoul, Korea
}

\begin{abstract}
In this paper, a tightly regulated triple output asymmetrical half bridge flyback (ASHF) converter is proposed. In order to regulate all output voltages, pulse frequency modulation (PFM), pulse width modulation (PWM) and phase delay (PD) are used simultaneously. In comparison with the conventional PWM-PD method, the interactions among the control variables are minimized and the operating range is increased. By the utilization of a multi winding transformer, the auxiliary transformer and the blocking capacitor are eliminated and the size and cost of the proposed converter is reduced. The operation principle of the converter is explained and the modes of operation are investigated. Based on the results, the steady state characteristics of the converter are explored. A $24 \mathrm{~V} / 10 \mathrm{~A}, 12 \mathrm{~V} / 5 \mathrm{~A}, 5 \mathrm{~V} / 10 \mathrm{~A}$ hardware prototype is built and tested to verify the analysis results and the voltage regulation of the triple outputs of the proposed converter.
\end{abstract}

Key Words: Asymmetrical half bridge flyback, PFM-PWM-PD method, Triple outputs

\section{INTRODUCTION}

Multiple output DC/DC converters are widely used in switched-mode power supplies (SMPS) due to their competitive cost and size. In order to achieve a tightly regulated output voltage, various post regulation schemes have been proposed. Representative realizations include synchronous switch post regulation (SSPR) which utilizes an auxiliary switch, PWMPD and PWM-PFM control, mag-amp approaches.

Among them, a multiple output converter using several control variables is advantageous in cost saving and size reduction because it operates without additional switches. A forward-flyback converter using the PWM-PFM method has been proposed [1], [2]. However, the voltage ratio between the two outputs is prefixed and the load range is highly limited.

An asymmetrical half bridge converter with PWM-PD control has been studied [3]. Although the output voltages are well regulated, the input voltage range is narrow and auxiliary circuitries are required for the third output.

In this paper, a tightly regulated triple output asymmetrical half bridge flyback converter (ASHF) is proposed. The converter is controlled by the proposed PFM-PWM-PD method and the interactions among the controllers are minimized. As a result, the input voltage and load range can be increased. In addition, the auxiliary transformer for the third output voltage in a conventional power stage is eliminated through the utilization of the multi windings from the existing transformers.

Manuscript received Aug. 17, 2009; revised Nov. 17, 2009

$\dagger$ Corresponding Author: novasa@ naver.com

Tel: +82-880-1785, Fax: +82-878-1452, Seoul National University

* Dept. of Electrical Eng., Seoul National University, Korea
This paper is organized as follows. The circuit configuration and operation principle of the proposed converter are explained in Section 2. In Section 3, the modes of operation of the proposed converter are examined. Then the steady state characteristics such as the dc voltage gains and the interactions among the three output voltages are investigated. A $320 \mathrm{~V}-400 \mathrm{~V}$ input range, $24 \mathrm{~V} / 10 \mathrm{~A}, 5 \mathrm{~V} / 10 \mathrm{~A}$ and $12 \mathrm{~V} / 5 \mathrm{~A}$ hardware prototype is built to demonstrate the performance of the proposed converter. The experimental results are illustrated in Section 4. The conclusions are summarized in Section 5.

\section{OPERATING PRINCIPLE OF THE PROPOSED PFM-PWM-PD METHOD}

A circuit diagram of the ASHF with the PWM-PD method referred to in [3] is shown in Fig. 1(a). The auxiliary transformer, $T_{3}$ and the blocking capacitor, $C_{b 3}$, are required for $v_{o 3}$. The ASHF PWM converter, which is a main topology of the proposed method, has been widely used as a front end $\mathrm{dc} / \mathrm{dc}$ converter due to the following advantages: 1) clamped switch voltage to the input voltage; 2) ZVS of MOSFETs and ZCS of the rectifier diode; 3 ) fixed switching frequency.

The operating principle of a conventional PWM-PD is shown in Fig. 2(a). The first and second output voltage, $v_{o 1}$ and $v_{o 2}$, are regulated using duty ratios of $S_{1}\left(D_{S 1}\right)$ and $S_{3}$ $\left(D_{S 3}\right)$ respectively. The third output voltage, $v_{o 3}$, is controlled by the phase delay ratio $\left(D_{p}\right)$ between the gate driving signals for $S_{1}$ and $S_{3}$. Since $D_{p}$ is generated by the difference between $D_{S 1}$ and $D_{S 3}$, the maximum range of $D_{p}$ is dependent on the actions of $v_{o 1}$ and $v_{o 2}$. This means the interactions among the converters are strong and the input voltage and the load range 


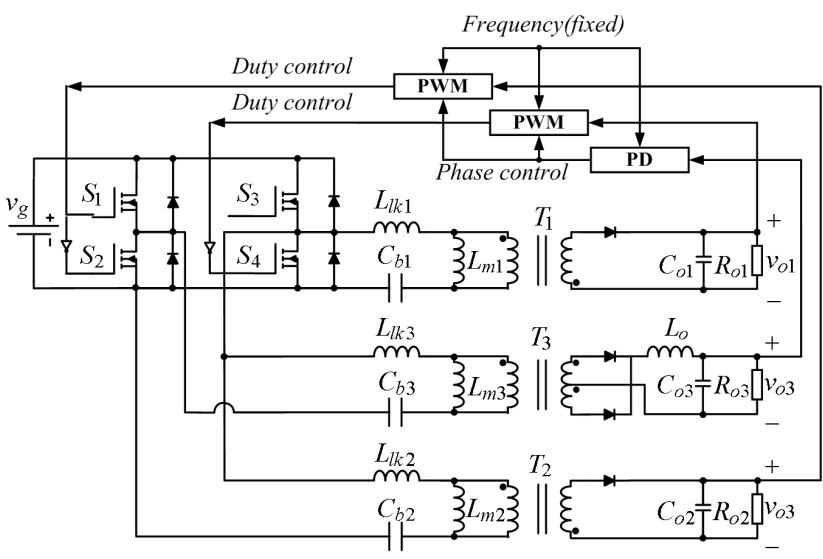

(a) The conventional ASHF converter with PWM-PD

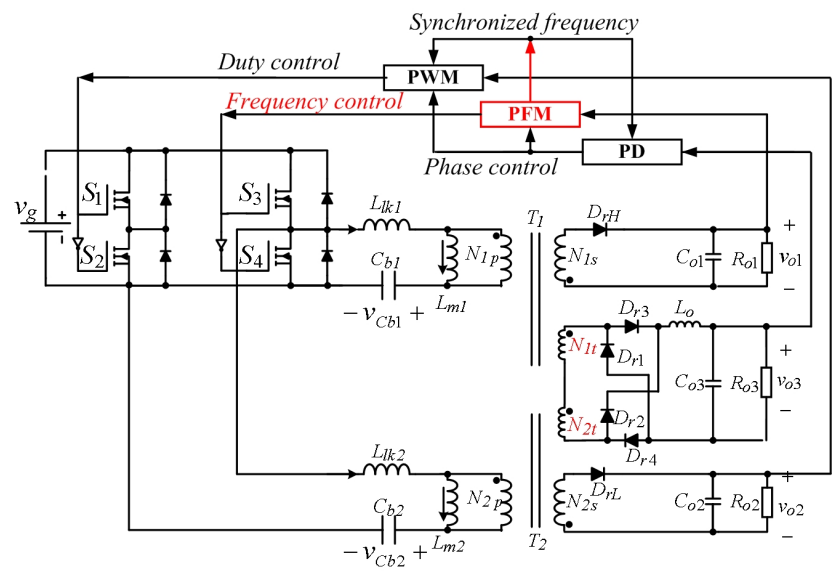

(b) The proposed ASHF converter with PFM-PWM-PD

Fig. 1. The circuit diagram of the conventional and proposed converter.

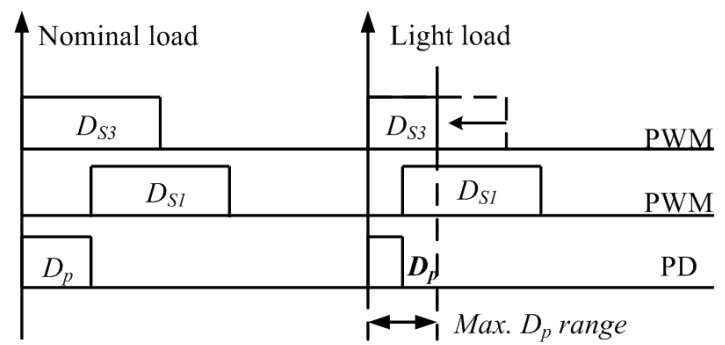

(a) PWM-PD control scheme

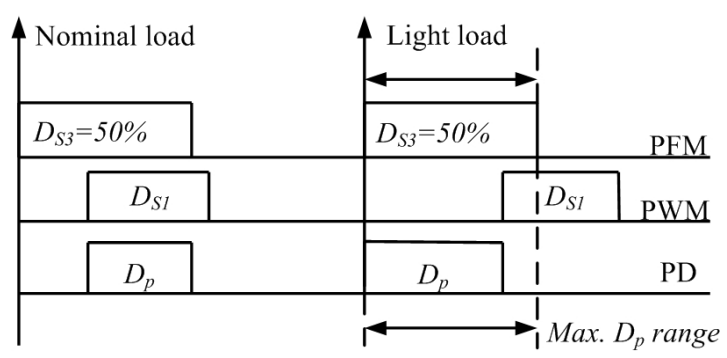

(b) Proposed PFM-PWM-PD control scheme

Fig. 2. Operating principle of the proposed converter.

are limited. These problems result in an increase in the input capacitance to satisfy the hold-up requirement [4].

In the proposed ASHF converter with the PFM-PWMPD method from Fig. 1(b), the transformer $T_{3}$ and the DC blocking capacitor $C_{b 3}$ in Fig. 1(a) are eliminated by utilizing the multi windings of the transformers, $T_{1}$ and $T_{2}$. Due to the connection of the multi windings, the voltages across the windings are similar to the conventional converter. The operating principle of the proposed converter is shown in Fig. 2(b). The PFM method is applied for the regulation of $v_{o 1}$ and its duty ratio, $D_{S 3}$, is fixed to $50 \%$. Thus, the maximum range for $D_{p}$ is equal to $D_{S 3}$ and it is independent of the load current. To reduce the interaction, $v_{o 2}$ is controlled by the PWM method which uses $D_{S 1}$ as a control variable in this paper.

\section{STEAdy STATE CHARACTERISTICS OF THE PROPOSED CONVERTER}

\section{A. Mode analysis of the proposed converter}

The modes of operation of the ASHF converter with PWM control have been explained in previous studies [5]-[9]. In this paper, the operations of the proposed converter which includes a dual ASHF and a multi winding transformer are investigated. The key operating waveforms of the proposed converter are shown in Fig. 3. To simplify the analysis, the current of $L_{o}$ is assumed to be constant.

$\operatorname{M} 1\left(t_{0}-t_{1}\right): S_{3}$ is turned on. The input voltage, $v_{g}$, increases the current of the magnetizing inductance, $L_{m 1}$. Due to the dot convention in the $T_{1}$, rectifier diode, $D_{r H}$, is turned off. $S_{2}$ is turned on and the stored energy in $C_{b 2}$ is released to $R_{o 2}$ through $L_{m 2}$ and $L_{l k 2}$. The equations are written as (1) and (2). The energy is transferred from $v_{g}$ to $v_{o 3}$ through the multi winding of $T_{1}$ and $T_{2}$. This mode ends when $S_{2}$ is turned off.

$$
\begin{aligned}
i_{L l k 1}(t)= & \frac{v_{g}-v_{C b 1}\left(t_{0}\right)}{Z_{o}} \sin \left(\omega_{o} t\right) \\
& +\left(\frac{N_{1 p} v_{o 3}}{N_{1 t} R_{o 3}}+i_{L m 1}\left(t_{0}\right)\right) \cos \left(\omega_{o} t\right) \\
v_{C b 1}(t)= & v_{C b 1}\left(t_{0}\right) \cos \left(\omega_{o} t\right)+v_{g}\left(1-\cos \left(\omega_{o} t\right)\right) \\
& +\left(\frac{N_{1 p} v_{o 3}}{N_{1 t} R_{o 3}}+i_{L m 1}\left(t_{0}\right)\right) Z_{o} \sin \left(\omega_{o} t\right)
\end{aligned}
$$

where, $\omega_{o}=\frac{1}{\sqrt{\left(L_{l k 1}+L_{m 1}\right) C_{b 1}}}, Z_{o}=\sqrt{\frac{L_{l k 1}+L_{m 1}}{C_{b 1}}}$

M2 $\left(t_{1}-t_{2}\right)$ : The body diode of $S_{1}$ is turned on by the negative current of $L_{l k 2}$. To achieve ZVS, $S_{1}$ is turned on during this period. Since the polarities of the voltage across $L_{l k 2}$ and $L_{m 2}$ are opposite, $i_{L l k 2}$ is increased and $i_{L m 2}$ is decreased. Thus, the current becomes zero due to the relation of (3) and then $D_{r L}$ is turned off softly.

$$
i_{D r L}(t)=\frac{N_{2 p}}{N_{2 s}}\left(i_{L l k 2}(t)-i_{L m 2}(t)\right)
$$




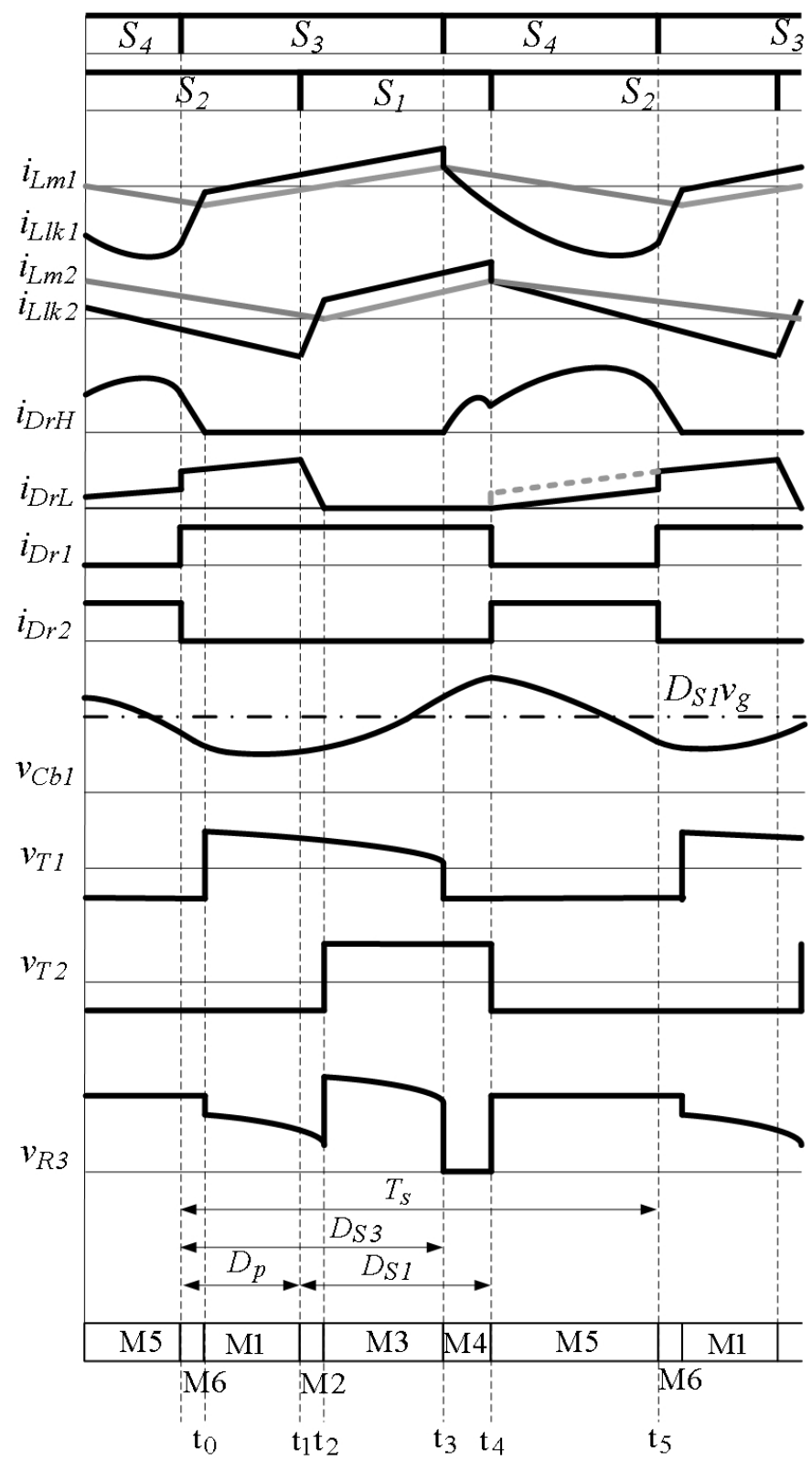

Fig. 3. The steady state waveforms of the proposed converter.

$\mathrm{M} 3\left(t_{2}-t_{3}\right): i_{L m 2}$ is increased linearly by $v_{g}$ and $C_{b 2}$ is charged through the current. The energy is transferred from $v_{g}$ to $v_{o 3}$ through $T_{1}$ and $T_{2}$. The current equation of this mode is expressed in (4).

$$
i_{L l k 2}(t)=i_{L m 2}\left(t_{2}\right)+\frac{v_{g}-V_{C b 2}}{L_{m 2}+L_{l k 2}} t+\frac{N_{2 p}}{N_{2 t}} I_{L o}
$$

where, $V_{C b 2}$ and $I_{L o}$ are the averaged values of $C_{b 1}$ and $L_{o}$. They are equal to $D_{S 3} v_{g}$ and the load current of $v_{o 3}$ respectively.

M4 $\left(t_{3}-t_{4}\right): S_{3}$ is turned off at $t_{3}$. The stored energy in $C_{b 1}$ is released to $R_{o 1}$ through $L_{l k 1}$. Thus, resonance between $L_{l k 1}$ and $C_{b 1}$ starts. $D_{r H}$ becomes conductive and the voltage across $L_{m 1}$ is clamped to the reflected $v_{o 1}$. The current and voltage equations in this mode are defined in (5) and (6).

$$
\begin{aligned}
& \begin{aligned}
v_{C b 1}(t)= & v_{C b 1}\left(t_{3}\right) \cos \left(\omega_{1} t\right)+i_{L l k 1}\left(t_{3}\right) Z_{1} \sin \left(\omega_{1} t\right) \\
& +\frac{N_{1 p}}{N_{1 s}} v_{o 1}\left(1-\cos \left(\omega_{1} t\right)\right) \\
i_{L l k 1}(t)= & i_{L m 1}\left(t_{3}\right) \cos \left(\omega_{1} t\right) \\
& +\frac{\frac{N_{1 p}}{N_{1 s}} v_{o 1}-v_{C b 1}\left(t_{3}\right)}{Z_{1}} \sin \left(\omega_{1} t\right)
\end{aligned} \\
& \text { where, } \omega_{1}=\frac{1}{\sqrt{L_{l k 1} C_{b 1}}}, Z_{1}=\sqrt{\frac{L_{l k 1}}{C_{b 1}}} .
\end{aligned}
$$

To achieve the monotonic slope in voltage gain for $v_{o 3}$ with respect to $D_{p}$, the turns ratios of $T_{1}$ and $T_{2}$ should be designed so that the voltage summation of $v_{T 1}$ and $v_{T 2}$ becomes almost zero during this period. Current commutation occurs in the rectifiers for $v_{o 3}$ due to a low $v_{R 3}$. Thus, the current of the tertiary winding in $T_{1}$ is reflected to the secondary winding and it is added to the reflected current from the primary winding. The increased $i_{D r H}$ during this mode is marked in Fig. 3.

M5 $\left(t_{4}-t_{5}\right)$ : The body diode of $S_{2}$ is turned on by the positive current of $L_{l k 2}$ and $L_{m 2}$. The stored energy in $C_{b 2}$ is released to $R_{o 2}$ and $i_{L l k 2}$ is linearly decreased because $v_{C b 2}$ is constant. $D_{r L}$ conducts and $L_{m 2}$ is reset by the reflected $v_{o 2}$. Thus, $i_{L m 2}$ is also decreased linearly. The current difference between $i_{L l k 2}$ and $i_{L m 2}$ flows to the load. The current equation of this mode is given by:

$$
i_{L l k 2}(t)=i_{L m 2}\left(t_{4}\right)-\frac{V_{C b 2}}{L_{m 2}+L_{l k 2}} t
$$

Due to the dot convention, the current relation in $T_{2}$ is expressed as (8). Thus, the reflected dc current of $I_{L o}$ is subtracted from the reflected current of the primary winding of $T_{2}$.

$$
i_{D r L}=\frac{1}{N_{2 t}}\left(N_{2 p}\left(i_{L l k 2}-i_{L m 2}\right)-N_{2 s} I_{L o}\right)
$$

M6 $\left(t_{5}-t_{6}\right): S_{4}$ is turned off and the body diode of $S_{3}$ conducts. Due to the positive voltage across $L_{l k 1}$, the current is increased while the current of $L_{m 1}$ is decreased by the reflected $v_{o 2}$. When the two currents meet, $D_{r H}$ is turned off softly due to the similar relation of (3).

\section{B. Voltage gains of the proposed converter}

The voltage gain of $v_{o 1}$ according to the switching frequency can be found from the modes of operation. To simplify the explanation, the transition modes, M2 and M6, are neglected because the time duration of these modes is much shorter than the switching period. Derivation of the voltage gain is similar to the LLC resonant converter case except that the resonant elements of the proposed converter only store the energy from the input voltage during $D_{S 1} T_{s}$. The resonant frequency of this period which is defined in (1) and (2) is used. The usage of the half wave rectifier is also considered. 

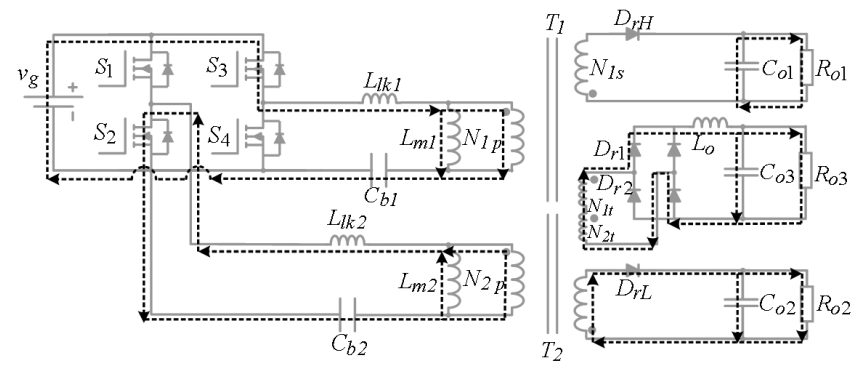

(a) M1
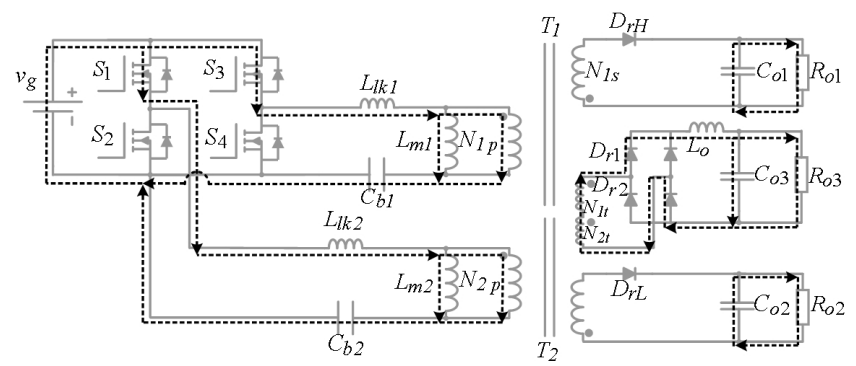

(c) M3
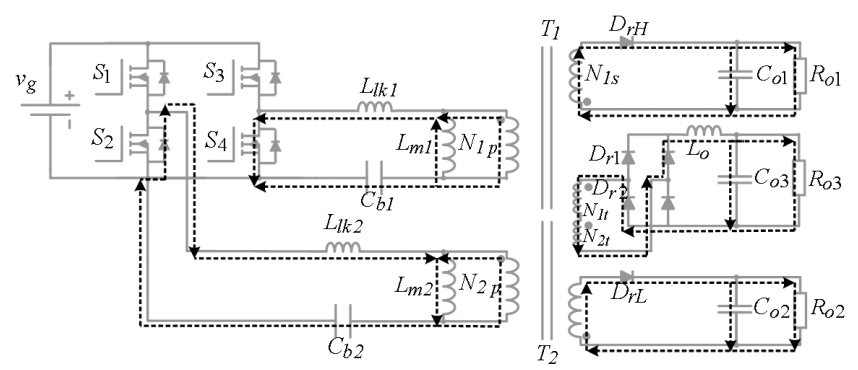

(e) M5
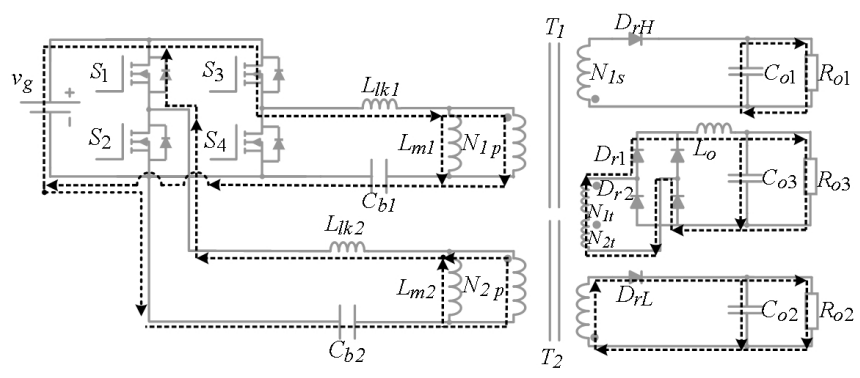

(b) M2
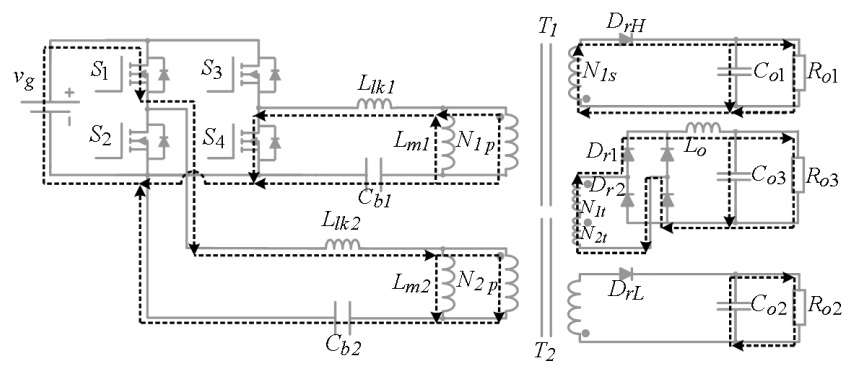

(d) M4
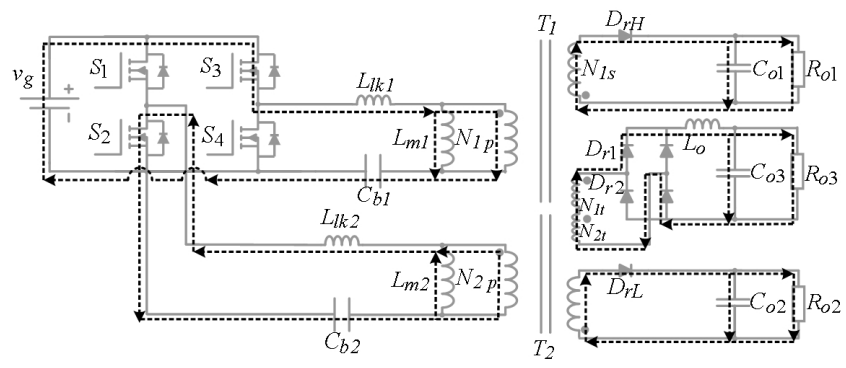

(f) M6

Fig. 4. The modes of operation of the proposed converter.

The voltage gain for $v_{o 1}$ is expressed as (9).

$$
\begin{aligned}
& M_{1}=\frac{v_{o 1}}{v_{g}}=\frac{2 N_{s 1} \sin \left(\frac{\pi D_{S 3}}{2}\right)}{N_{p 1} \sqrt{\left(\frac{k_{1}+1}{k_{1}}-\frac{1}{\omega_{n}^{2}}\right)^{2}+Q^{2}\left(\frac{1}{\omega_{n}}-\omega_{n}\right)^{2}}} \\
& Q=\frac{Z_{2}}{R_{a c}}, R_{a c}=\frac{4 R_{o 1} N_{p 1}^{2}}{\pi^{2} N_{s 1}^{2}}, k_{1}=\frac{L_{l k 1}}{L_{m 1}}, \omega_{n}=\frac{\omega_{s}}{\omega_{2}} \\
& Z_{2}=\sqrt{\frac{L_{m 1}}{C_{b 1}}}, \omega_{2}=\frac{1}{\sqrt{L_{m 1} C_{b 1}}}, k_{2}=\frac{L_{l k 2}}{L_{m 2}}
\end{aligned}
$$

where, $\omega_{2}$ is the modified resonant frequency, $Z_{2}$ is the modified characteristics impedance, $\omega_{n}$ is the normalized switching frequency, $Q$ is the quality factor, $R_{a c}$ is the reflected load resistance to the primary side of $T_{1}$ while $k_{1}$ and $k_{2}$ are the inductance ratios between the magnetizing and resonant inductance. The obtained voltage gain for $v_{o 1}$ is compared with the results of the circuit simulation. The PLECS toolbox in MATLAB with a practical switching circuit model is utilized. It shows that the simplified analytical voltage gain function is good enough to obtain the initial design strategies for all load conditions.
The voltage gain for $v_{o 2}$ was found in previous studies [5][9] because it is controlled by the PWM method. Due to the inductive output filter in Fig. 1(b), the averaged value of the rectified voltage, $v_{R 3}$, is the same as $v_{o 3}$. To find out the relation between $v_{o 3}$ and $D_{p}$, the waveforms in Fig. 3 are used. For the steady state voltage gain, the average value of $v_{C b 1}$ is used to obtain a simple design equation.

$$
v_{C b 1} \cong D_{S 3} v_{g}
$$

The winding voltages of the primary side in $T_{1}$ and $T_{2}$ through the multi windings are summarized in Table 1. Applying (11), the gains for the other output voltages in fixed switching frequency can be approximated.

$$
\frac{V_{o 1}}{v_{g}} \cong \alpha \frac{N_{1 s}}{N_{1 p}} D_{S 3}, \frac{V_{o 2}}{v_{g}} \cong \frac{N_{2 s}}{N_{2 p}} D_{S 1}
$$

The compensation factor, $\alpha$, should be multiplied because the voltage gain for $v_{o 1}$ is affected by the switching frequency and $\alpha$ is obtained from the gain curve in Fig. 5. $v_{o 3}$ is calculated by the averaged value listed in Table 1 . The approximated voltage gain is shown in Fig. 6 . The slope of the voltage gain becomes zero when $D_{p}$ is less than $\left(D_{S 3}-D_{S 1}\right)$. This means 
TABLE I

RECTIFIED WINDING VOLTAGE $\left(v_{R 3}\right)$ AND OPERATING MODE

\begin{tabular}{|c|c|c|c|c|c|}
\hline \multicolumn{3}{|c|}{$D_{S 3} \leq D_{S 1}+D_{p}$} & \multicolumn{3}{|c|}{$D_{S 3}>D_{S 1}+D_{p}$} \\
\hline mode & $v_{R 3}$ & time duration & mode & $v_{R 3}$ & time duration \\
\hline M5 & $\left|-\frac{N_{1 t}}{N_{1 s}} v_{o 1}-\frac{N_{2 t}}{N_{2 s}} v_{o 2}\right|$ & $\begin{array}{l}\left.1-D_{S 3}\right) \\
-\left(D_{S 1}+D_{p}-D_{S 3}\right) \\
\end{array}$ & M5 & $\left|-\frac{N_{1 t}}{N_{1 s}} v_{o 1}-\frac{N_{2 t}}{N_{2 s}} v_{o 2}\right|$ & $\left(1-D_{S 3}\right)$ \\
\hline M1 & $\frac{N_{1 t}\left(1-D_{S 3}\right) v_{g}}{N_{1 p}\left(1+k_{1}\right)}-\frac{N_{2 t}}{N_{2 s}} v_{o 2}$ & $D_{p}$ & M1 & $\left|\frac{N_{1 t}\left(1-D_{S 3}\right) v_{g}}{N_{1 p}\left(1+k_{1}\right)}-\frac{N_{2 t}}{N_{2 s}} v_{o 2}\right|$ & $D_{p}$ \\
\hline M3 & $\frac{N_{1 t}\left(1-D_{S 3}\right) v_{g}}{N_{1 p}\left(1+k_{1}\right)}+\frac{N_{2 t}\left(1-D_{S 1}\right) v_{g}}{N_{2 p}\left(1+k_{2}\right)}$ & $D_{S 3}-D_{p}$ & M3 & $\frac{N_{1 t}\left(1-D_{S 3}\right) v_{g}}{N_{1 p}\left(1+k_{1}\right)}+\frac{N_{2 t}\left(1-D_{S 1}\right) v_{g}}{N_{2 p}\left(1+k_{2}\right)}$ & $D_{S 1}$ \\
\hline M4 & $-\frac{N_{1 t}}{N_{1 s}} v_{o 1}+\frac{N_{2 t}\left(1-D_{S 1}\right) v_{g}}{N_{2 p}\left(1+k_{2}\right)}$ & $D_{S 1}+D_{p}-D_{S 3}$ & M4 & $\left|\frac{N_{1 t}\left(1-D_{S 3}\right) v_{g}}{N_{1 p}\left(1+k_{1}\right)}-\frac{N_{2 t}}{N_{2 s}} v_{o 2}\right|$ & $\begin{array}{l}D_{S 3} \\
-\left(D_{S 1}+D_{p}\right)\end{array}$ \\
\hline
\end{tabular}

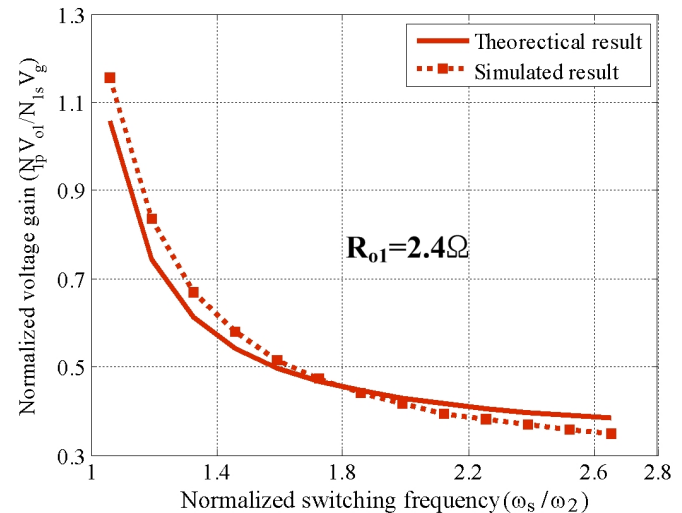

(a) Voltage gain @ $R_{o 1}=2.4 \Omega$

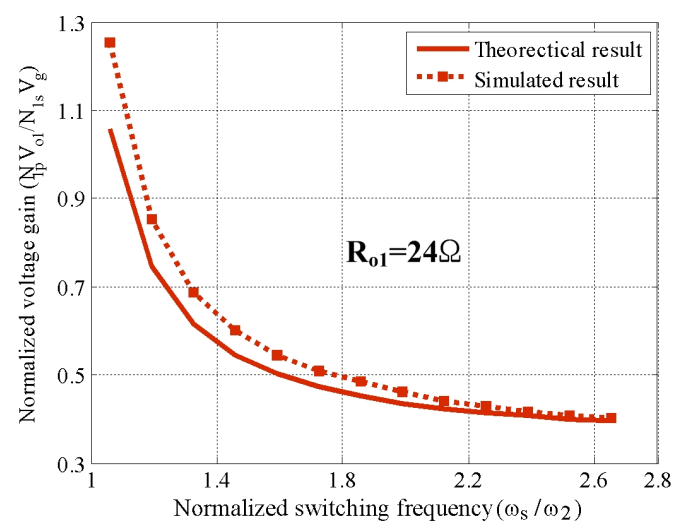

(b) Voltage gain @ $R_{o 1}=24 \Omega$

Fig. 5. Gain comparison between the model in (9) and Switching circuit simulation.

that the effect of a phase delay occurs within the overlapped area between $D_{S 3}$ and $D_{S 1}$. Also, the operating range of $D_{p}$ is limited by $D_{S 3}$. Thus, the minimum for $D_{S 1}$ is required to prevent abnormal operation.

To verify the analytical gain function, the voltage gain for $v_{o 3}$ is obtained through the switching circuit simulation as shown in Fig. 7. The gain difference between the analytical and simulated result is small when $D_{S 1}$ is low, but as $D_{S 1}$ increases, the error becomes large. However, the approximated gain curve can be used in the initial design process.

The interactions between the three output controls are

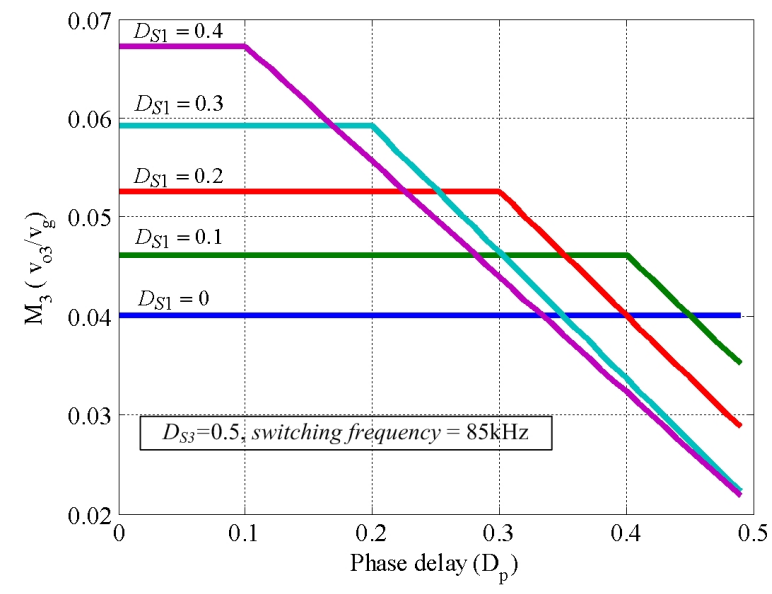

Fig. 6. Approximated gain curve for $v_{o 3}$ according to $D_{S 1}$ and $D_{p}$.

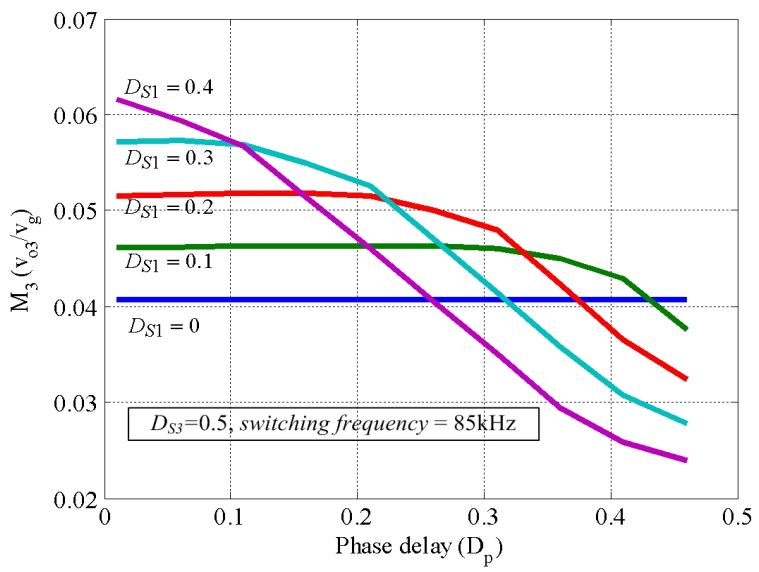

Fig. 7. Simulated gain curve for $v_{o 3}$ according to $D_{S 1}$ and $D_{p}$.

investigated. The effects of $D_{S 1}$ and $D_{p}$ in $v_{o 1}\left(M_{1}\right)$ are illustrated in Fig. 8. When $f_{s}=120 \mathrm{kHz}$ and $f_{s}=150 \mathrm{kHz}$, almost no variations are observed (flat planes). This means the variations according to $D_{S 1}$ and $D_{p}$ variances are negligible during operation. Although a small variation is observed in the low switching frequency $(85 \mathrm{kHz})$, it is less than 0.01 .

The effects of $D_{p}$ and $f_{s}$ in $v_{o 2}\left(M_{2}\right)$ are shown in Fig. 9. It is observed that $M_{2}$ is not affected by the variation of $D_{p}$ and $f_{s}$ when $D_{S 1}=0$ and 0.2 . In the case of $D_{S 1}=0.4$, the 
TABLE II

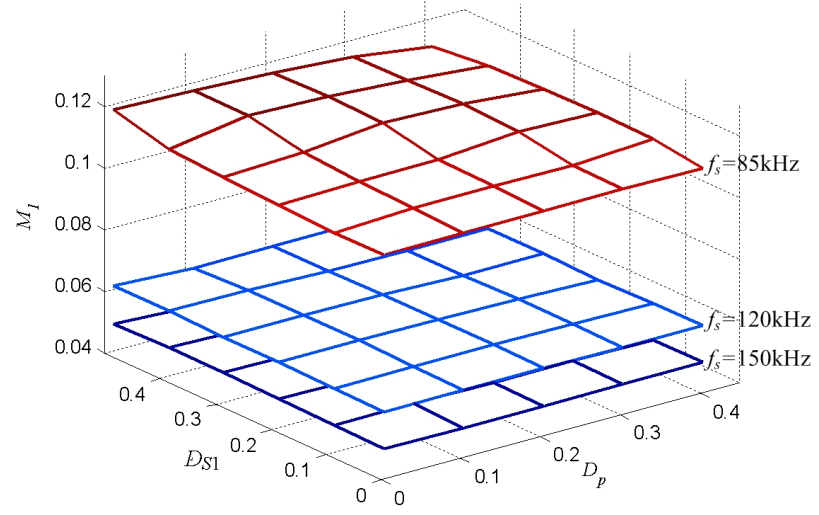

Fig. 8. The interactions of $D_{S 1}$ and $D_{p}$ to $M_{1}$.

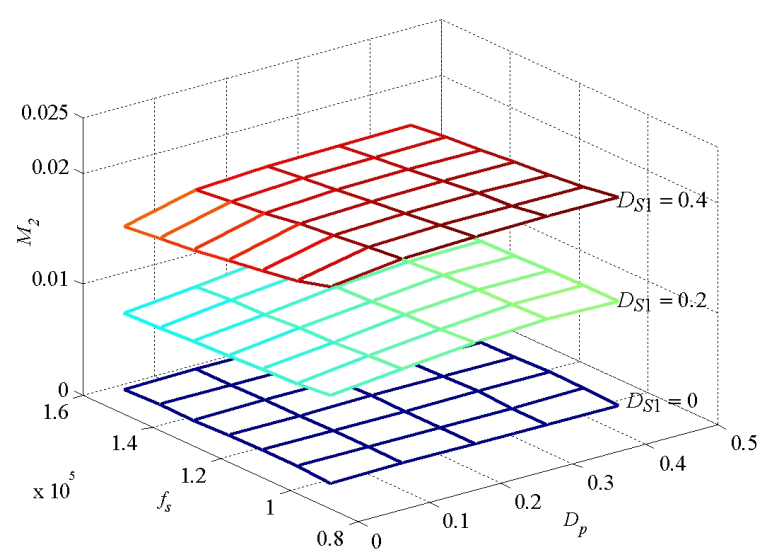

Fig. 9. The interactions of $f_{s}$ and $D_{p}$ to $M_{2}$.

variation is less than 0.005 .

From the results, the interactions among the control variables are small in the PFM-PWM-PD method. Therefore the input and load range can be widened.

\section{EXPERIMENTAL VERIFICATION}

In this section, a hardware prototype is built and tested to verify the analysis results and to demonstrate the voltage regulation of the three output voltages in the proposed converter. The designed circuit parameters are listed in Table 2. $T_{1}$ is manufactured using the sectional winding technique in [10]. The leakage inductance of $T_{1}$ is utilized as a series resonant inductor. A small size output filter inductor using a bar type ferrite core is applied to $L_{o}$.

To verify the output voltage regulation of the proposed converter three feedback loops with a dsPIC33FJ16GS502 are implemented. The steady state waveforms under $380 \mathrm{~V}$ of input voltage are shown in Fig. 10. The waveforms and phase delay are similar to the analysis results in Fig. 3.

The experimental dc voltage gain for $v_{o 3}$ is measured and shown in Fig. 12. The curves show good agreement with the result in Fig. 7.
THE PARAMETERS OF THE PROPOSED CONVERTER

\begin{tabular}{|c|c|c|c|}
\hline Device & Value & Device & Value \\
\hline$c_{o 1}$ & $6 \mathrm{mF}$ & $N_{1 p}: N_{1 s}: N_{1 t}$ & $17: 2: 1$ \\
\hline$c_{o 2}$ & $13.2 \mathrm{mF}$ & $N_{2 p}: N_{2 s}: N_{2 t}$ & $42: 3: 3$ \\
\hline$c_{o 3}$ & $1.5 \mathrm{mF}$ & $L_{m 1} / L_{l k 1}$ & $135 \mathrm{uH} / 45 \mathrm{uH}$ \\
\hline$T_{1}$ & EER4950s & $L_{m 2} / L_{l k 2}$ & $300 \mathrm{uH} / 50 \mathrm{uH}$ \\
\hline$T_{2}$ & EER3542s & $L_{o}$ & $3.3 \mathrm{uH}$ \\
\hline MOSFET & FQA18N60 & Core for $L_{l k 2}$ & EI20 \\
\hline Diode & KCH30A10 & $C_{b 1}$ & $33 \mathrm{nF}$ \\
\hline$f_{s}(\mathrm{kHz})$ & $80-140$ & $C_{b 2}$ & $1 \mathrm{uF}$ \\
\hline Core for $L_{o}$ & \multicolumn{4}{|c|}{ Bar core $(\varphi=6] \mathrm{mm}, l=35 \mathrm{~mm})$} \\
\hline
\end{tabular}

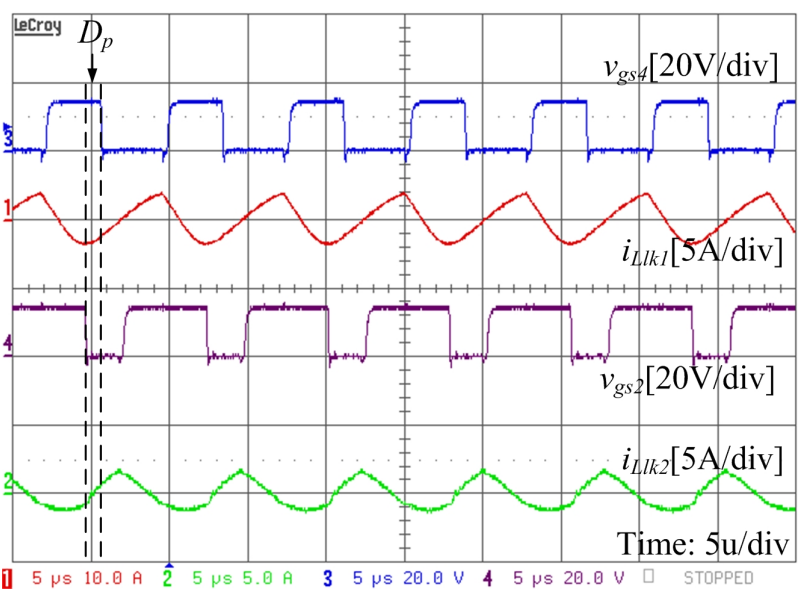

Fig. 10. The steady state waveforms under $@ v_{g}=380 \mathrm{~V}$, full load.

The results of the output voltage regulation are illustrated in Fig. 11. The load current is changed from $10 \%$ to $100 \%$. For the step load change of $i_{o 1}$, the voltage variation (in Fig. 11(a)) of $v_{o 1}$ is less than $2 \mathrm{~V}(8.3 \%)$ in the transient period using a PFM control loop. Almost no voltage variations are observed in $v_{o 2}$ and $v_{o 3}$. In the case of an experiment where $i_{o 2}$ is changed, $v_{o 2}$ is also well regulated by PWM control and a small variation is shown in Fig. 11(b). In the case of a change in $i_{o 3}, v_{o 3}$ is regulated less than $2 \mathrm{~V}$ in the transient period. The other output voltages are regulated within $0.5 \mathrm{~V}$. In the steady state, all output voltage variations according to the load current are almost zero as shown in Fig. 11.

\section{Conclusions}

This paper proposes a tightly regulated triple output ASHF converter with PFM-PWM-PD control. The auxiliary circuitries in the conventional approach such as a transformer and a blocking capacitor are eliminated by the utilization of the multi windings of the proposed converter. The modes of operation were explained and the steady state characteristics were investigated. From the analysis result, the minimum interactions among the control variables were verified. The proposed converter and control scheme were implemented with a $24 \mathrm{~V} / 10 \mathrm{~A}, 5 \mathrm{~V} / 10 \mathrm{~A}$ and $12 \mathrm{~V} / 5 \mathrm{~A}$ hardware prototype using a 16bit digital controller. The measured voltage gain and operating waveforms verified the analysis results and tight output voltage regulation in the steady state for different loads was confirmed. 


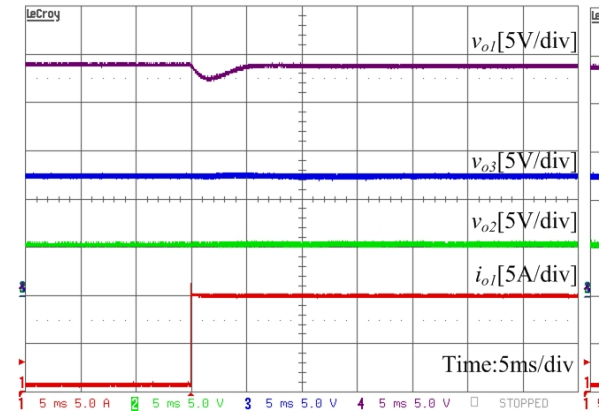

(a) $i_{o 1}: 1 \mathrm{~A} \rightarrow 10 \mathrm{~A}$

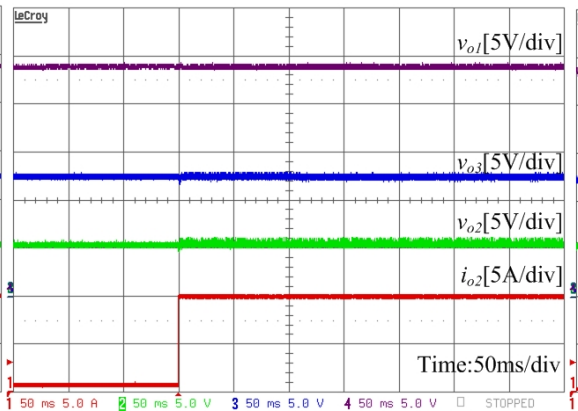

(b) $i_{o 2}: 1 \mathrm{~A} \rightarrow 10 \mathrm{~A}$

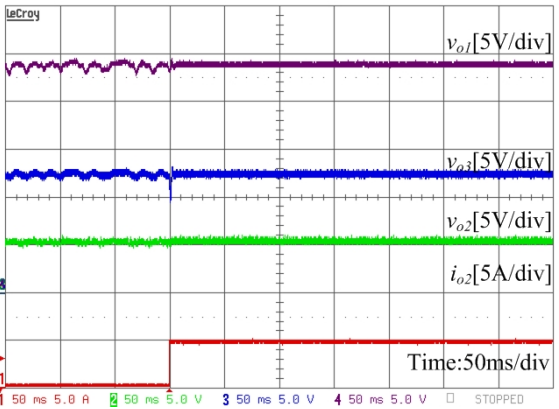

(c) $i_{o 3}: 0.5 \mathrm{~A} \rightarrow 5 \mathrm{~A}$

Fig. 11. The regulation performances of the output voltages respect to the load change.

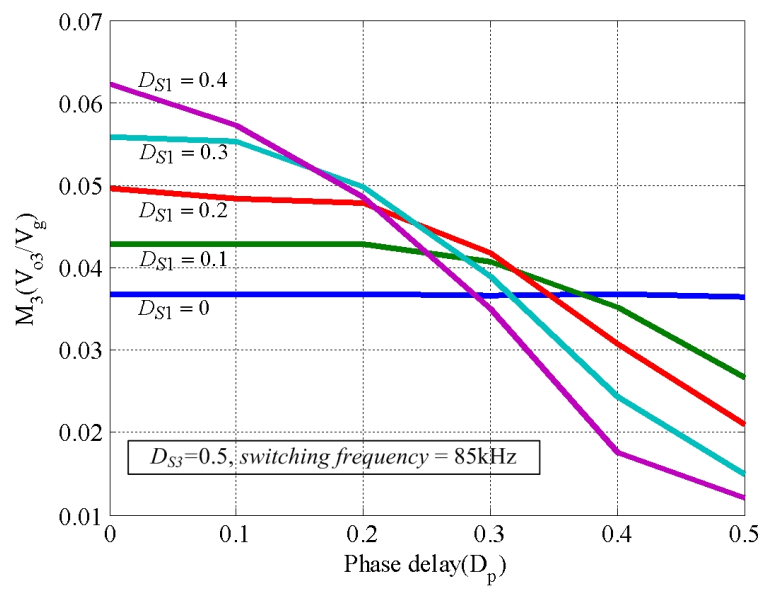

Fig. 12. The measured voltage gain $\left(M_{3}\right)$ according to $D_{S 1}$ and $D_{p}$.

\section{REFERENCES}

[1] J. Sebastian and J. Uceda, "The Double Converter: A Fully Regulated Two-Output DC-DC Converter," Power Electronics, IEEE Transactions on, Vol. PE-2, pp. 239-246, 1987.

[2] H. E. Tacca, "Single-switch two-output flyback-forward converter operation," Power Electronics, IEEE Transactions on, Vol. 13, pp. 903-911, 1998.

[3] Yanjun Zhang and Dehong Xu, "Design and Implementation of an Accurately Regulated Multiple Output ZVS DC-DC Converter," Power Electronics, IEEE Transactions on, Vol. 22, pp. 1731-1742, 2007.

[4] Y. T. Jang, M. M. Jovanovic, and D. L. Dillman, "Hold-up time extension circuit with integrated magnetics," in Applied Power Electronics Conference and Exposition, 2005. APEC 2005. Twentieth Annual IEEE, Vol. 1, pp. 219-225, 2005.

[5] D. H. Seo, O. J. Lee, S. H. Lim, and J. S. Park, "Asymmetrical PWM flyback converter," in Power Electronics Specialists Conference, 2000. PESC 00. 2000 IEEE 31st Annual, Vol. 2, pp. 848-852, 2000.

[6] Han Li, W. Zhou, S. Zhou and Xiao. Yi, "Analysis and design of high frequency asymmetrical half bridge flyback converter," in Electrical Machines and Systems, 2008. ICEMS 2008. International Conference on, pp. 1902-1904, 2008.

[7] J. H. Jung and J. G. Kwon, "Soft switching and optimal resonance conditions of APWM HB flyback converter for high efficiency under high output current," in Power Electronics Specialists Conference, 2008. PESC 2008. IEEE, pp. 2994-3000, 2008.

[8] T. M. Chen and C. L. Chen, "Small-Signal Modeling of Asymmetrical Half Bridge Flyback Converter," in Power Electronics and Motion Control Conference, 2006. IPEMC 2006. CES/IEEE 5th International, pp. 1-5, 2006.

[9] J. H. Jung, J. M. Choi and J. G. Kwon, "Design Methodology for Transformers Including Integrated and Center-tapped Structures for LLC Resonant Converters," Journal of Power Electronics, Vol. 9, pp. 215-223, 2009.

[10] H. S. Choi, "Design Consideration of Half-Bridge LLC Resonant Converter," Journal of Power Electronics, Vol. 7, pp. 13-20, 2007.

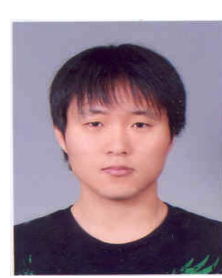

(KIPE).

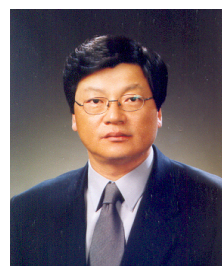

Bo-Hyung Cho received his B.S. and M.E. degrees in Electrical Engineering from the California Institute of Technology, Pasadena. He received his Ph.D. also in Electrical Engineering, from Virginia Polytechnic Institute and State University (Virginia Tech), Blacksburg, Virginia. Prior to his research at Virginia Tech, he worked for two years as a technical staff member in the Power Conversion Electronics Department at the TRW Defense and Space System Group. From 1982 to 1995 , he was a professor in the Department of Electrical Engineering at Virginia Tech. He joined the school of Electrical Engineering at Seoul National University, Seoul, Korea in 1995 and he is presently a Professor. His main research interests include power electronics, modeling, analysis and control of spacecraft power processing equipment, power systems for space stations and space platforms, and distributed power systems. Prof. Cho received the 1989 Presidential Young Investigator Award from the National Science Foundation. $\mathrm{He}$ is a member of Tau Beta Pi. 